\title{
Grack-fabrication techniques and their effects on the fracture toughness and CTOD for fresh-water columnar ice
}

\author{
Y. Wei, S.J. DeFranco and J. P. Dempsey \\ Department of Civil and Environmental Engineering, Clarkson University, \\ Potsdam, New York 13699-5710, U.S.A.
}

\begin{abstract}
The effects of notch acuity (crack-tip sharpness) on the fracture toughness of S2 ice were investigated using six groups of single-edge-notched-bend (SENB) specimens with different crack (or notch) root radii fabricated by six different methods. The mean value and standard deviations of the apparent fracturetoughness values $K_{\mathrm{Q}}$ of the specimens with blunt notches were significantly higher than those of the specimens with sharp cracks. The results presented in a plot of fracture toughness versus $\rho^{\frac{1}{2}}$, where $\rho$ is the crack-tip radius, provide an estimate of the required notch acuity for fracture-toughness testing. The microstructural features in the immediate vicinity of the crack tip and the crack-tip geometry govern the magnitude of the apparent fracture toughness of the ice. The crack-tipopening-displacement (CTOD) measured in this study indicates the existence of microplastic deformation in the vicinity of the crack tip at the initiation of unstable fracture.
\end{abstract}

\section{INTRODUCTION}

One of the most important aspects in fracture-toughness testing is the fabrication of a truly sharp crack for linear elastic fracture mechanics (LEFM) to apply. This is accomplished by making a fatigue crack in a specimen for metallic materials (ASTM E399-83, 1985). Attempts to introduce a fatigue crack in an ice specimen, however, proved unsuccessful (Goodman, 1977). It is believed that ice has little tendency to suffer fatigue damage because of its low stacking-fault energy (Cole, 1990). In a material with low stacking-fault energy like ice (Hondoh and others, 1983), cross slip is difficult and dislocations are constrained to move in a more planar fashion. This limits local concentrations of plastic deformation and suppresses fatigue damage (Dieter, 1986).

Since there is no standard method available for the fracture-toughness testing of ice, different methods for machining or forming cracks have been introduced into the fracture literature for various types of ice. Kusumoto and others (1986) attempted to fabricate a crack in a specimen by inserting a razor blade into the specimen during freezing. Dempsey and others (1989) utilized a procedure of pressing and freezing a razor blade into the notch tip of a specimen just prior to the test. Nixon and Schulson (1988) used a machine-held razor blade to sharpen a cylindrical notched specimen. Perhaps the most common practice for ice specimens has been to sharpen a notch by a hand-held razor blade or scalpel (Hamza and Muggeridge, 1979; Kollé, 1981; Danilenko, 1985; Timco and Frederking, 1986). Attempts were also made to machine repeatable notches using either a band saw or a wire saw (Dempsey and others, 1989) and to form a V-notch by pushing a razor blade into the bottom of a slot of a specimen (Liu and Loop, 1972; Goodman and Tabor, 1978).

The wide scatter in the fracture-toughness values of ice cited in the literature to date (summarized for S2 ice by Bentley and others (1989) and Dempsey (1989)) has made necessary a thorough examination of the various testing influences on the frature toughness. For example, the apparent fracture toughness of S2 ice has been found to vary from 50 to $400 \mathrm{kPa} \mathrm{m}^{\frac{1}{2}}$. The different procedures for preparing the crack prior to testing are believed to be one of the major factors causing the scatter. In this context, inserting a razor blade into a specimen during its freezing naturally causes a microstructural variation in the ice close to the blade. Cutting a notch by a band saw leaves a blunt notch tip in the specimen; the calculation of the association geometry-dependent criticalstress-intensity factor is therefore not strictly applicable. Although hand-held razor blades may well sharpen a crack, this results in a nucleated crack of uneven length, and the repeatability and reliability of this method remain to be confirmed.

In the light of the above comments, it is necessary 
to make a thorough evaluation of the various methods used to fabricate cracks in ice. This has led to a study of the effects of notch acuity on the fracture toughness of S2 fresh-water ice. The dependence of the frature toughness on the notch-tip radius is well known for other materials, such as H-11 steel (Irwin, 1964), mild or low-carbon steel at low temperatures (Wilshaw and others, 1968; Yokobori and Konosu, 1977), ceramic materials (Bertolotti, 1973; Pabst, 1974) and aluminum metal matrix composites (Manoharan and Lewandowski, 1989). In this study, tests were conducted on six groups of single-edgenotched-bend (SENB) specimens with cracks fabricated by six different methods, viz, drilling a small hole at the crack tip, a band saw, a wire saw, pressing and freezing a razor blade at the crack tip, using a hand-held razor to sharpen the crack and pre-cracking. The apparent fracture toughness values $K_{\mathrm{Q}}$ (following the notation introduced by Dempsey (in press)) of each group are determined as well as their mean values and the standard deviations.

The attempt to measure the crack-tip opening displacement (CTOD) was considered an important phase of this study. Although the CTOD measurement is more often required for high-toughness materials, a reliable CTOD value provides significant information from which an indirect determination of $K_{\mathrm{Q}}$ and a measure of the process-zone size at the crack tip are possible for various types of ice.

\section{EXPERIMENTAL PROCEDURE}

The ice type used in this testing program was S2 freshwater ice which is the seeded fine columnar polycrystalline ice having horizontal or near-horizontal $c$-axis orientations, as classified by Michel and Ramseier (1971). This type of ice has been grown in an insulated tank measuring $1.22 \mathrm{~m} \times 1.14 \mathrm{~m} \times 0.78 \mathrm{~m}$ in the cold room at Clarkson University by the following process. The temperature of the cold room was set to $-18^{\circ} \mathrm{C}$. The tap water in the tank was cooled to about $1^{\circ} \mathrm{C}$ at the top surface and $3-4^{\circ} \mathrm{C}$ beneath the surface before seeding began. Seeding was performed by spraying a very fine mist upwards above the surface of the water. This mist froze to fine ice crystals in the air before reaching the water surface, acting as crystal nuclei to enable the water to solidify heterogeneously. Four sheets of S2 ice were used for fracture and flexure tests in this study. The procedures for growing these ice sheets were kept the same. A careful examination of the $c$-axis orientations by measuring 120 grains for each ice sheet indicated that all these four ice sheets had the same type of textural features having the $c$-axes of most grains of the ice sheets randomly and horizontally or near-horizontally oriented. The diameters of the columnar grains of the S2 ice showed a slight increase with depth. This minor variation of grain-size with depth was not considered a serious problem since the thicknesses of the ice sheets were only about $50 \mathrm{~mm}$. The average grain-sizes of these sheets, measured from the middle horizontal sections were found to have a slight difference, varying from 2.26 to $2.52 \mathrm{~mm}$.

The single edge-notched beam with three-point-bend loading configuration was used for the fracture tests (Fig. 1). The nominal dimensions of the specimens were:

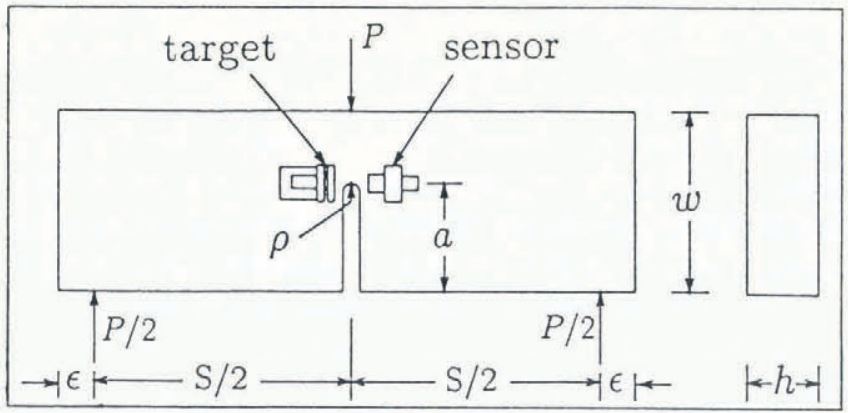

Fig. 1. Single edge-notched beam geometry and proximity gage set-up.

width $w=100 \mathrm{~mm}$, support span $S=300 \mathrm{~mm}$, thickness $h=50 \mathrm{~mm}$ and crack length $a=50 \mathrm{~mm}$. Twelve such specimens were tested for each group. All of the data obtained is reported in the Appendix. The tests were carried out on an ATS universal test machine at a crosshead speed of $7.62 \mathrm{mms}^{-1}$ so that all the specimens broke in less than $5 \mathrm{~s}$ (with $\dot{K}$ values ranging within $\left.60-200 \mathrm{kPa} \mathrm{m}^{\frac{1}{2}} \mathrm{~s}^{-1}\right)$. After the notch or crack was introduced in each specimen, the fracture test was conducted as soon as possible to avoid sublimation or healing of the notch or crack tip. A highly sensitive displacement gage, Kaman KD-2810-1U, was attached on one side of the specimen (Fig. 1) to measure the crack-tip opening displacement (CTOD). The resolution of the gage is less than $0.25 \mu \mathrm{m}$, and its linear measuring range is $25 \mu \mathrm{m}$. The data-acquisition system consisted of a Zenith Z-248 computer and a Keithly Series 500 measurement and control system with a reading rate of 1000 readings/s. This system, including the micro-displacement gages, made an accurate record of the histories of loading and CTOD possible. The formula for the calculation of apparent fracture toughness is given as follows (Go and others, 1984):

$$
K_{\mathrm{Q}}=P_{\mathrm{f}} F(a / w) / h w^{\frac{1}{2}}
$$

in which

$$
\begin{aligned}
F(\eta) & =3\left\{-1.186(1-\eta)^{2}+2.474(1-\eta)-6.858\right. \\
& \left.+8.124(1-\eta)^{-1}+0.045(1-\eta)^{-2}\right\} / 4
\end{aligned}
$$

where $P_{\mathrm{f}}$ is the load at fracture and the symbol $K_{\mathrm{Q}}$ is used instead of $K_{\mathrm{Ic}}$, as recommended by Dempsey (in press) to represent the apparent fracture toughness of S2 ice.

The formation of notches and cracks was accomplished by different methods for the specimens of each group. A drill of $1.95 \mathrm{~mm}$ diameter was used to drill a small hole at the notch root of the specimens of group A (of a crack initially formed using a band saw). The average root radius was measured to be $1.1 \pm 0.08 \mathrm{~mm}$. The notches in the specimens of group B were simply cut by a band saw, resulting in a rectangular-ended root of width $1.8 \pm 0.2 \mathrm{~mm}$. The notches in specimens of group $\mathrm{C}$ were fabricated by a wire saw with a diamond-coated wire $0.2 \mathrm{~mm}$ in diameter; the root radii were found to be $0.28 \div 0.04 \mathrm{~mm}$. Following Dempsey and others (1989), for the specimens of group D, a razor blade coated on 
both faces with a low-temperature teflon spray lubricant was positioned in a notch cut by a band saw. Just before the razor blade was positioned, lukewarm water was jetted into the notch with an eyedropper. As the water froze (in about $15 \mathrm{~s}$ ), the blade was moved gently back and forth to prevent the blade from freezing to the newly formed ice. A certain amount of pressure was exerted to ensure that the very tip of the razor blade was actually in the S2 ice, and not in the ice just formed in the sawed notch. The tip radius formed in the specimen was established to be approximately $0.01 \mathrm{~mm}$ (see the details described in the next section). For the specimens of group $\mathrm{E}$, the notches were cut by a band saw and sharpened by a hand-held razor blade just prior to test, resulting in a naturally sharp crack of uneven length about $2 \mathrm{~mm}$ long.

A pre-cracking procedure was performed to introduce naturally sharp cracks for the specimens of group F. Each specimen was notched by a band saw to a length slightly less than half the specimen depth $(w \approx 100 \mathrm{~mm})$. The specimens were then placed in the three-point bend apparatus which was in position on the loading platform. The crosshead was lowered until a pre-load of $40-50 \mathrm{~N}$ was applied to the specimen. The crosshead motion was immediately stopped and it was noticed in each case that the pre-load dropped slightly $(5-6 \mathrm{~N})$ because of creep deformation and minor position adjustments in the three-point loading apparatus. A hand-held razor was then gently scribed across the root of the band-sawcut notch thereby generating a naturally sharp, although wavy, crack front. The new crack length formed was approximately $2-4 \mathrm{~mm}$ in length; this increment is slightly longer than that for group E. The introduction of the sharp crack dropped the pre-load to approximately $10 \mathrm{~N}$ in each case. The fracture test was then performed as quickly as possible; the time interval between formation of the sharp crack and the fracture test was less than $20 \mathrm{~s}$ due to the pre-cracking procedures being performed with a specimen pre-set in the testing position.

For groups $\mathrm{E}$ and $\mathrm{F}$, the crack length used in the $K_{\mathrm{Q}}$ calculation for each specimen was the sum of the bandsaw-cut notch and the average length of the naturally sharp crack. All machining, storage and testing was performed at $-10^{\circ} \mathrm{C}$.

Despite the apparent success of measuring the CTOD on the three-point SENB specimens, it is imperative that uncertainties in the measuring procedures be mentioned. The Kaman KD-2810-1U gages used in the CTOD measurement must be parallel to the non-magnetic target (T6061 aluminum) within $0.5^{\circ}$ to ensure accurate measurements. As the specimen surfaces on to which the sensor and target were frozen were fairly rough, it is possible that misalignment could occur. Additionally, as the Kaman sensor is very sensitive (static resolution $\approx 0.025 \mu \mathrm{m})$, the measured CTOD is the actual CTOD in addition to the sensor-target displacement caused by flexural rotation and by the fact that in order to measure the CTOD the measuring equipment and its target must be attached on opposite sides of the crack. However, in response to the above statements, a SENB specimen of $\mathrm{S} 2$ ice under three-point loading is very brittle at the test temperature and will not rotate $0.5^{\circ}$ at the midspan of the beam and therefore it is believed that rotational effects may be neglected here. The target and measuring device will move apart from each other during loading by an amount equal to the average strain times the distance between them. Judging by similar tests on other materials, this additional COD adds approximately 5$10 \%$ to the actual CTOD. No corrections are made to the measurements reported in this paper.

Out-of-plane rotation may also be neglected as this will probably not induce any significant in-plane displacement thereby not affecting the CTOD measurement. As the experiments were performed very carefully, it is believed that the surface roughness of the specimen along with positioning error associated with mounting the sensor and target did not cause a substantial CTOD measurement error.

\section{NOTCH-TIP GEOMETRIES AND CRACK INITIATION}

Examinations of the specific notch-tip geometries and the characteristics of each crack-initiation event were carried out on thin sections showing the notch shapes and the crack paths of the specimens. These thin sections were made by matching the halves of the broken specimens and fixing the microtomed samples of the matched specimens to a glass slide by cyanoacrylate glue. The orientation of each thin section with respect to the crack path is sketched in Figure 2. Note that the notch front is parallel to the columnar grains of the specimen. The results of the observations of the crack path are shown in Figure 3.

Figure $3 \mathrm{a}-\mathrm{f}$ corresponds to the typical fractures observed in groups $\mathrm{A}-\mathrm{F}$, respectively. The thin sections clearly reveal that the notch width of the specimens of groups A and B was as large as the grain-size (Fig. 3a and b). Obviously, the requirements of LEFM for very sharp cracks is not satisfied by these blunt notches. The shape of the notch tips of the specimens of group A (drilling a hole) were semi-circular, and crack initiation was most often observed to begin from the central part of the notch front. For the specimens with the notch cut by a band saw (group B), cracking from the corners of the rectangular-ended roots was most common. A similar situation was reported on the fracture tests for S1 ice (Dempsey and others, 1988); in fact, such fractures often "ignore" most of the pre-cut crack front, leading, in S1 ice, to "hill"-type fracture initiation followed by conchoidal brittle intergranular fracture (Dempsey, 1990).

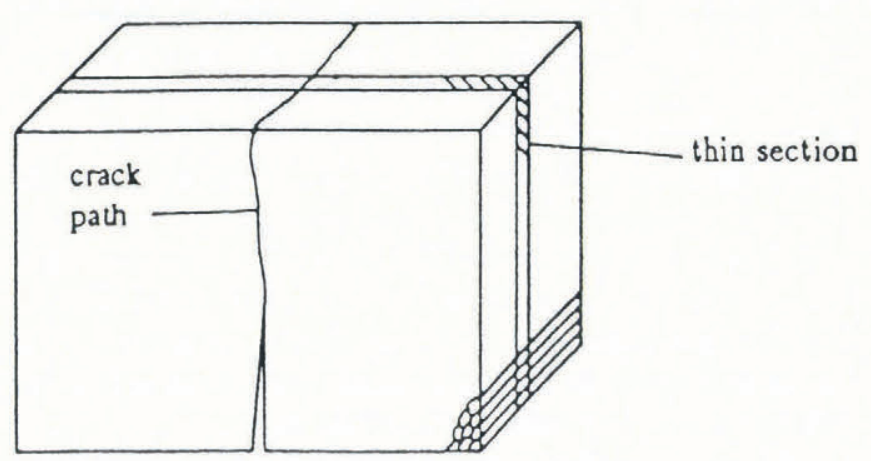

Fig. 2. The orientation of thin section with respect to crack path. 


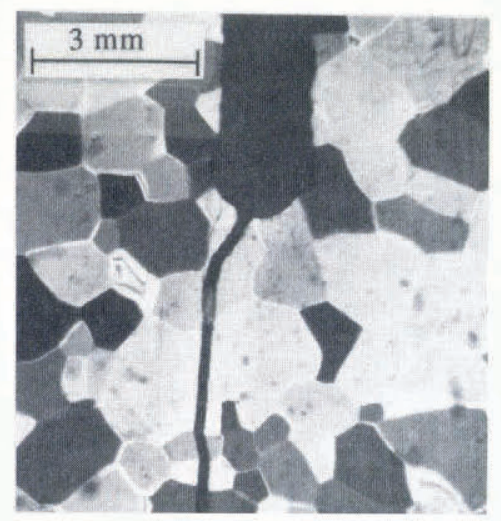

(a)

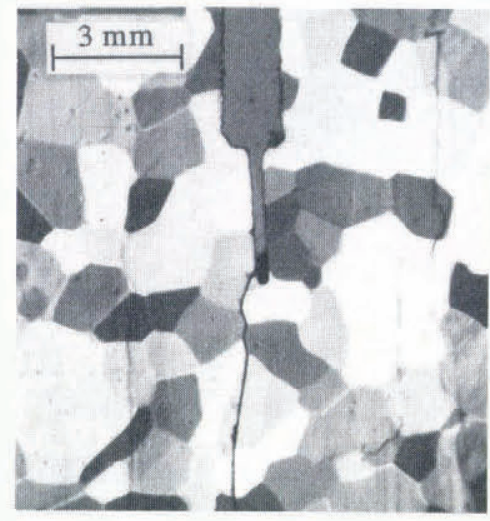

(c) CI1

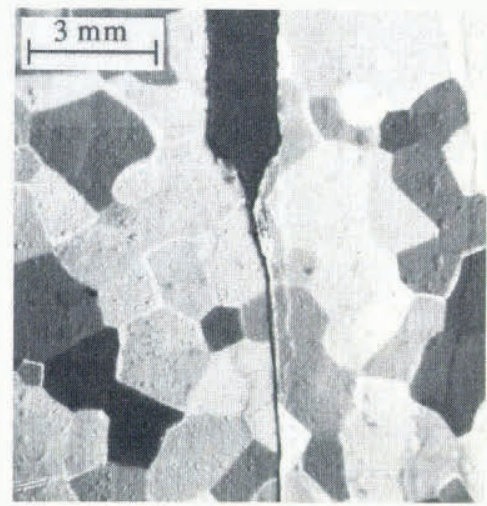

(e)

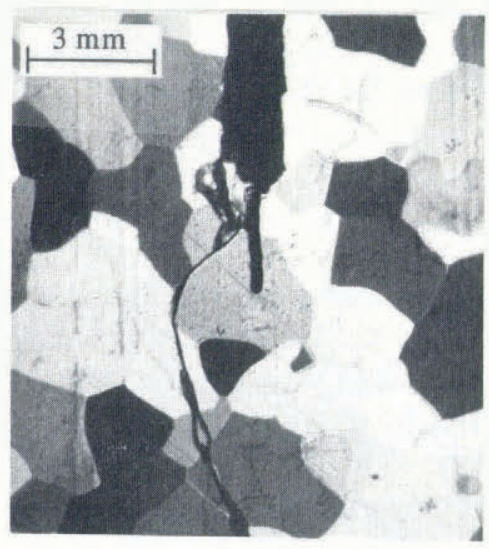

(g)
CVI3

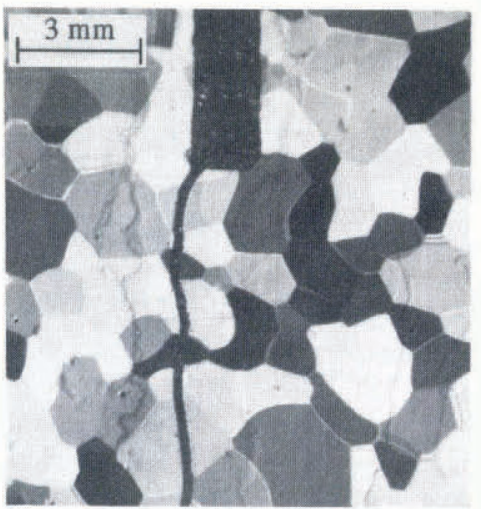

(b)

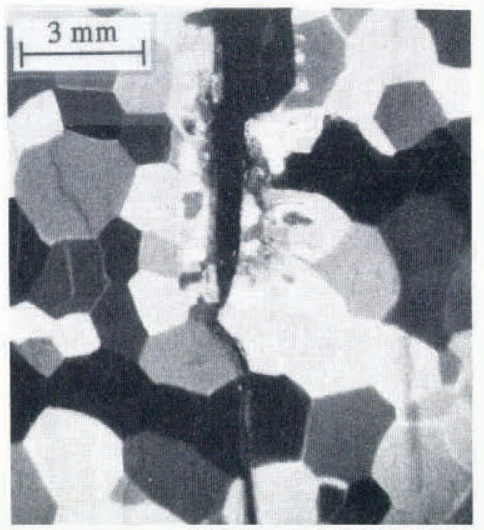

(d)

DV1

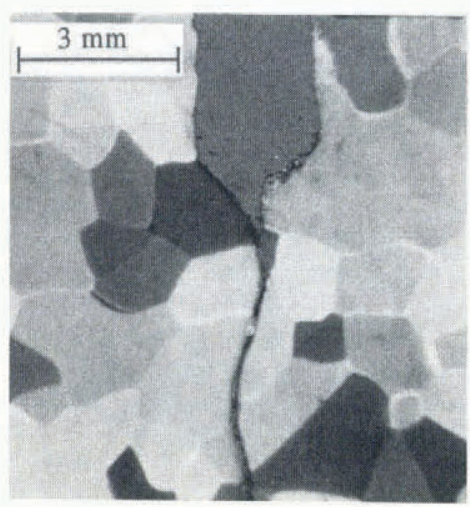

(f)

FII1

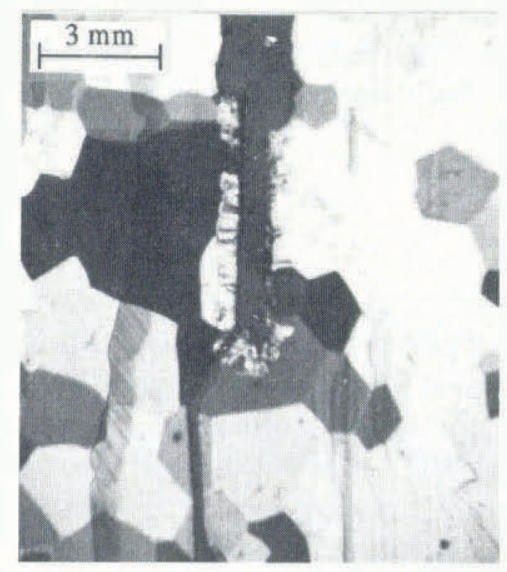

(h)

DI3

Fig. 3. Crack orientation and crack path (photographed under crossed polarizers): test specimens (a) AVI1, (b) BVI3, (c) CI1, (d) DV1, (e) EI3, (f ) FII1, (g) CVI3 and (h) DI3. 


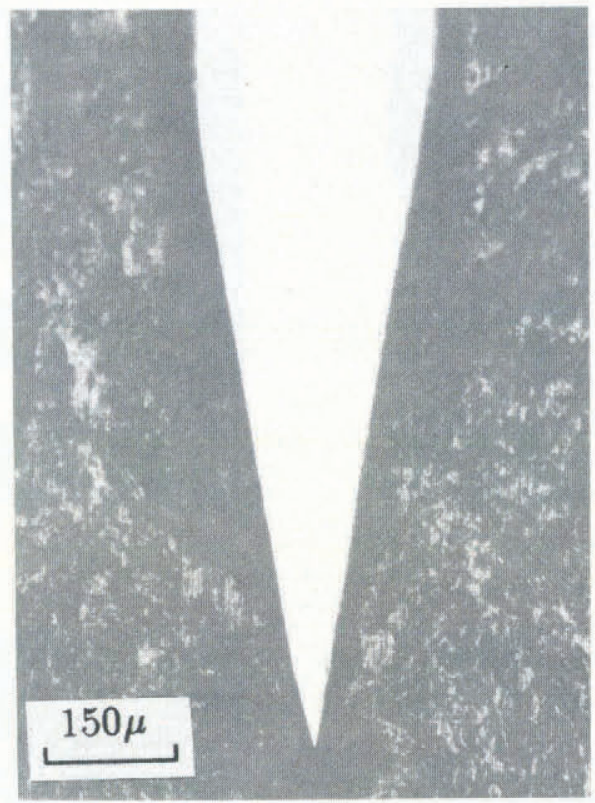

(a)

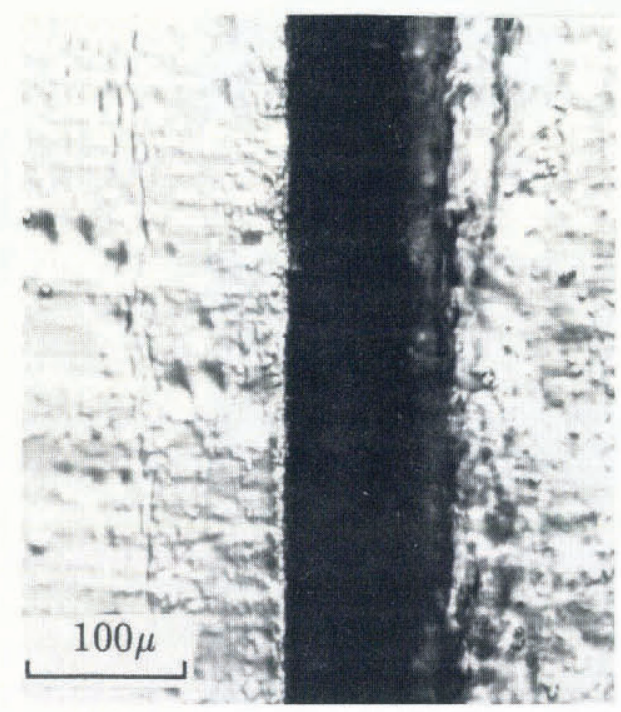

(b)

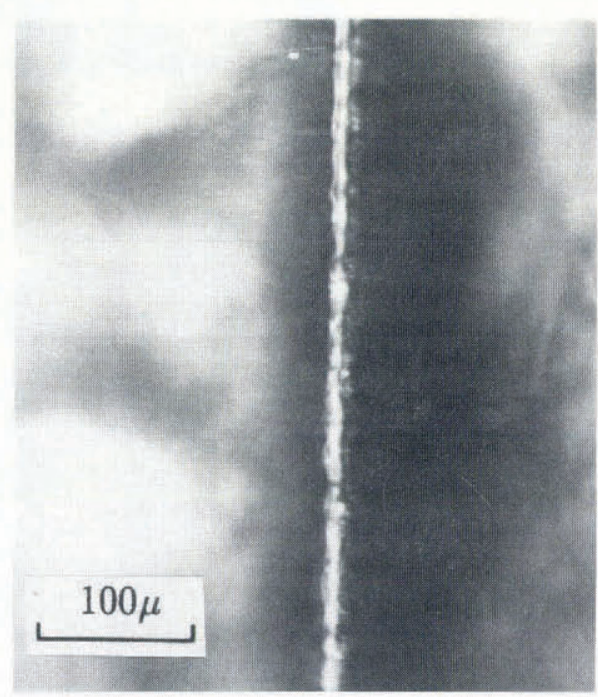

(c)

Fig. 4. (a) Tip shape of the razor blade. (b) Notch shape in the surface plane of the ice sample (photographed with Hoffmann modulation contrast). (c) The shape and the size of the notch root formed in the ice sample (photographed with Hoffmann modulation contrast).

This is not surprising, since the stress is theoretically singular at the re-entrant corners (Williams, 1952).

Having realized that the maximum principal stress possibly exists at some distance ahead of a blunt notch (Griffiths and Owen, 1971), particular attention was paid to the type of fracture initiation, expecting that the different fracture types would be associated with different fracture-toughness values. In groups $\mathrm{A}$ and $\mathrm{B}$, both transgranular and intergranular fracture were found in the grains next to the notch tips. Although the highest $K_{\mathrm{Q}}$ values were found for the specimens showing trans- granular fracture in the first grain in front of the notch tip, statistically, there is no distinguishing evidence to account, solely by the fracture mechanisms, for the difference in the $K_{\mathrm{Q}}$ values of the specimens of these two groups. The orientation of the favored cleavage planes (for transgranular fracture) or the grain boundaries (for integranular fracture) of the grains in front of the notch tip may have an important influence on the apparent fracture toughness of the material. The minor damage in the notch surface introduced during the formation of the notches (i.e. during cutting or drilling) might pos- 
sibly also influence the site of crack initiation. These uncertainties must have been among the factors which caused the scatter in $K_{\mathrm{Q}}$ values of groups $\mathrm{A}$ and $\mathrm{B}$.

Surprisingly, cracking rarely initiated from the tip of the notch of the specimens examined in group $\mathrm{C}$; these specimens had much narrower notches fabricated by a wire saw with a fine diamond-coated wire. Two typical samples are presented in Figure $3 \mathrm{c}$ and g. Clearly, the cracks of both specimens failed to initiate from the tip of the notches. Perhaps the most significant features in these two pictures pertain to the location of the notch tip in the local microstructure. For specimen CI1 (Fig. $3 \mathrm{c})$, the notch tip ended at a grain boundary shared by three columnar grains but the beginning of cracking is transgranular in nature and not from the notch tip. Coincidentally, this specimen showed the lowest $K_{\mathrm{Q}}$ value in group C. For specimen CVI3 (Fig. 3g), on the other hand, the notch tip ended in the center of a columnar grain. Before the stress near the notch tip reached a level high enough to cause a cleavage fracture for this grain, cracking initiated from a weak point from one crack face and well behind the notch tip, initially propagating along a grain boundary. The $K_{\mathrm{Q}}$ value of this specimen was one of the highest in group $\mathrm{C}$, double that of specimen CI1. Furthermore, for the specimens with the notch tip ending inside a grain, their $K_{\mathrm{Q}}$ values were higher than the mean value. Those specimens with notch tip ending at a grain boundary showed $K_{\mathrm{Q}}$ values lower than the mean value. Obviously, the location of the notch tip and the particular microstructural features present in the vicinity of the notch tip play an important role in the site and type of fracture initiation as well as the magnitude of the fracture toughness at initiation.

At this juncture, therefore, three of the methods (drilling a hole, a band saw, a wire saw) seem to have little practical utility for the realistic measurement of the fracture toughness of ice, although they may well prove useful in establishing the effects of notch acuity on the fracture toughness for various types of ice.

The method of formation of the notch for the specimens of group $\mathrm{D}$ requires that the razor blade be moved back and forth under hand-applied pressure. This operation is meant to ensure that the sharp tip of the razor blade is actually in the $\mathrm{S} 2$ ice, but at the same time this back and forth motion detracts from the final sharpness obtained. In other words, the actual notch-root radius so acquired in the S2 ice is larger than that of the tip of the razor blade. To establish approximately this notch-root radius, the surface of a piece of $\mathrm{S} 2$ ice was microtomed and a groove in the surface was made by moving a razor blade back and forth under hand-applied pressure, similar to the precedure used to make sharp cracks for group D. The shape and the size of the notch root formed can be examined photographically. Figure 4 a shows the tip shape of the type of razor blade used, obtained using a phenolic molding powder. The notch-root radius was established by adopting the Hoffman modulation contrast technique, using an optical microscope (Olympus Model $\mathrm{BH} 2$-UMA, capable of magnification up to $\times 500)$. It is possible using this technique to focus both at the surface of the ice sample (Fig. 4b) and at the object plane on which the notch root lies (Fig. 4c). The half-width of the notch root photographed was taken to be the notch-root radius, and was found to be approximately $0.01 \mathrm{~mm}$.

It was expected that a crack tip sharp enough to satisfy the requirements of LEFM with a uniform crack front would be obtained for the specimens of group D. Examinations of the crack-tip geometries of the specimens indicated that in most specimens the blade tip did not penetrate into the S2 ice body very deeply; however, this procedure did help the crack to initiate uniformly from the tip of the notch (Fig. 3d). In one test specimen (DI3), the razor blade did not penetrate the S2 ice at all but was embedded in the just-formed ice frozen by the jetted water during the crack-formation effort. In this case, the crack did not propagate from the notch tip, but from a weak point behind the tip (Fig. $3 \mathrm{~h}$ ). Significantly, the $K_{\mathrm{Q}}$ value of this specimen was much higher than the rest of the values in group D and was disregarded in the calculation of the mean and standard-deviation values. There was no such problem in the fracture of groups $\mathrm{E}$ and $\mathrm{F}$.

A more effective crack-formation procedure is suggested by the specimens from either group $\mathrm{E}$ or group F. Both methods require that a sharp crack be scribed in by a hand-held razor blade; this scribing nucleates sharp cracks about $2-4 \mathrm{~mm}$ ahead of the notches cut by a band saw (Fig. 5). These sharp cracks are now believed to satisfy the requirements of LEFM. For the specimens observed, crack growth was found to initiate only from the "scribed-in" crack tips, regardless of where each crack tip ended (Fig. 3e and f). Again, the $K_{\mathrm{Q}}$ values of a specimen with the crack tip located inside a grain was higher than that with the crack tip located on a
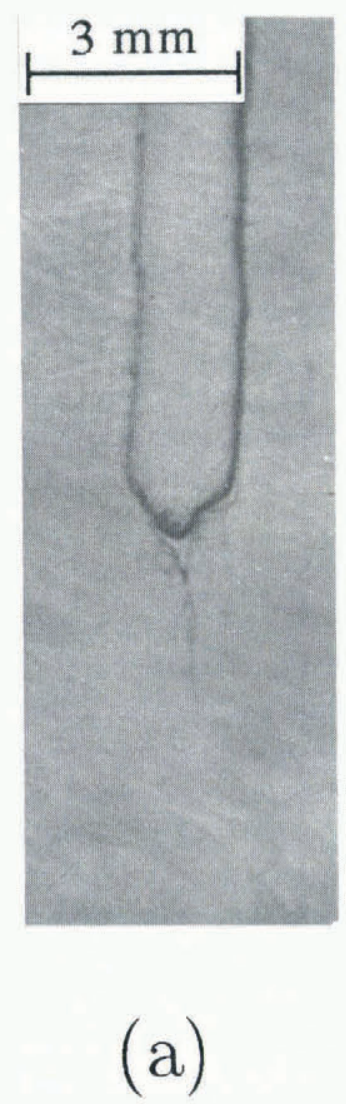

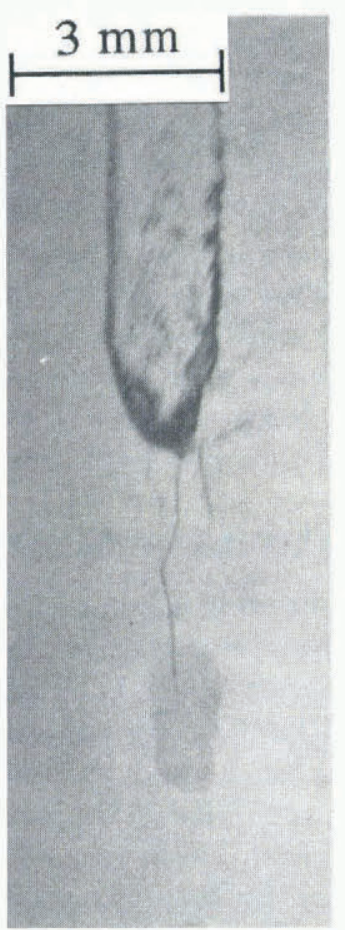

(b)
Fig. 5. Naturally sharp cracks introduced for the specimens of (a) group $E$, (b) group $F$ (photographed under a polarizer). 
Table 1. $K_{\mathrm{Q}}$ and CTOD for each group

\begin{tabular}{|c|c|c|c|c|c|c|}
\hline \multirow[t]{2}{*}{ Group } & \multirow[t]{2}{*}{$\begin{array}{c}\rho \\
\mathrm{mm}\end{array}$} & \multirow[t]{2}{*}{$\begin{array}{c}\text { No. of } \\
\text { tests }\end{array}$} & \multicolumn{2}{|c|}{$\begin{array}{c}K_{\mathrm{Q}} \\
\mathrm{kPa} \mathrm{m}^{1 / 2}\end{array}$} & \multicolumn{2}{|c|}{$\begin{array}{l}C T O D \\
\mu \mathrm{m}\end{array}$} \\
\hline & & & $x$ & $\sigma_{\mathrm{n}}$ & $x$ & $\sigma_{\mathrm{n}}$ \\
\hline A & 1.10 & 12 & 180.64 & 61.32 & 1.58 & 0.71 \\
\hline B & 0.90 & 12 & 189.82 & 45.29 & 1.42 & 0.30 \\
\hline $\mathrm{C}$ & 0.28 & 11 & 135.97 & 45.00 & 1.00 & 0.33 \\
\hline D & 0.01 & 11 & 87.90 & 9.50 & 0.62 & 0.12 \\
\hline $\mathrm{E}$ & 0.00 & 12 & 96.86 & 8.06 & 0.72 & 0.25 \\
\hline $\mathrm{F}$ & 0.00 & 12 & 97.74 & 8.10 & 0.70 & 0.19 \\
\hline
\end{tabular}

Note: $x$ is mean value; $\sigma_{\mathrm{n}}$ is standard deviation, $\rho$ is cracktip radius (groups A, C, D, E and F) or half-slot width (group B).

A: drilling a hole; B: cut by band saw; C: cut by wire saw; D: freeze-in-place razor blade; E: hand-held razor blade, zero pre-load; F: hand-held razor blade, nominal pre-load.

grain boundary. This observation, together with the information regarding the mean values and standard deviations in Table 1, reinforces the conclusions that scribing with a hand-held razor blade under conditions of either zero pre-load or a small pre-load are suitable methods for fabricating the initial naturally sharp macrocrack in the fracture-toughness testing of ice. Of these two methods, the operation of sharpening a crack by a hand-held razor blade with no pre-load is much simpler; however, the pre-cracking procedure produces a longer naturally sharp crack. Both methods offer the same advantage: the repeatability of these procedures is better than any of the other procedures (Table 1).

\section{RESULTS AND DISCUSSION}

The mean values and standard deviations of the apparent fracture toughness $K_{\mathrm{Q}}, \mathrm{CTOD}$ and the crack-tip radius (groups A, C, D, E and F) or the half-slot width (group B) $\rho$ of the specimens of each group are summarized in Table 1, using the information listed in the Appendix. From Table 1 , the means of the $K_{\mathrm{Q}}$ values of groups $\mathrm{A}$, B and C were $40-117 \%$ higher than those of groups D, E and $\mathrm{F}$. There is a slight problem with the measurement for group D which will be discussed later. Clearly, the apparent fracture toughness of S2 ice is highly dependent on the crack-tip radius or "notch acuity". There was no significant difference between the mean values of $K_{\mathrm{Q}}$ and CTOD of groups $\mathrm{E}$ and $\mathrm{F}$. Also noticeable were the much smaller standard deviations of $K_{\mathrm{Q}}$ values for these two groups compared with groups A, B and C. This implies that a stable $K_{\mathrm{Q}}$ value can be obtained by either of these
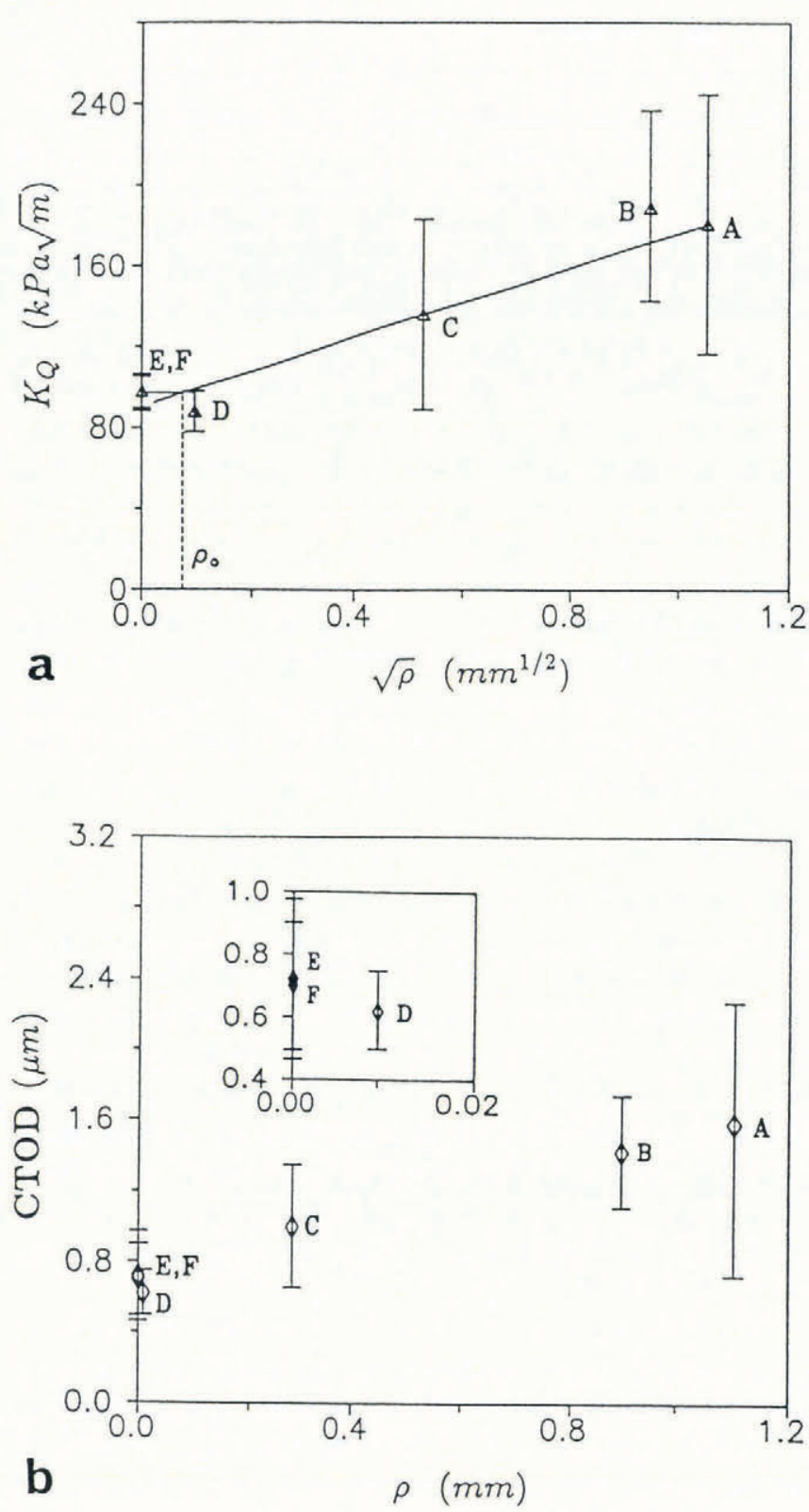

Fig. 6. Effects of notch-root radii on apparent fracture toughness $K_{Q}$ and CTOD: (a) $K_{Q}-\rho^{\frac{1}{2}}$ relation; (b) CTOD- $\rho$ relation; $\rho$ is the cracktip radius $(A, C, D, E$ and $F$ ) or the half-slot width (B).

two procedures, namely, using a hand-held razor blade to sharpen the crack or pre-cracking.

The relationship between $K_{\mathrm{Q}}$ and $\rho^{\frac{1}{2}}$ is shown in Figure $6 \mathrm{a}$, which has been plotted using the $K_{\mathrm{Q}}$ and the $\rho$ values of groups $\mathrm{A}-\mathrm{F}$. For metallic materials there is a critical value $\rho_{0}$ above which $K_{1 \mathrm{c}}$ had a linear dependence on $\rho^{\frac{1}{2}}$ and below which the plane-strain fracture toughness $K_{\text {Ic }}$ is obtained (Irwin, 1964; Wilshaw and others, 1968 ; Knott, 1973). No such critical value $\rho_{0}$ was definitely established by this study; however, the results do indicate that a similar dependency holds for ice. The $K_{\mathrm{Q}}$ values for group D were somehow lower than those of groups $\mathrm{E}$ and $\mathrm{F}$. A statistical hypothesis test showed that the mean $K_{\mathrm{Q}}$ values of group D and group $\mathrm{E}$ (or $\mathrm{F}$ ) were significantly different. However, this difference was possibly caused by the lubricant used to coat the razor 
blades that were frozen in place. The procedure of jetting water into the notch to freeze the blade in place also created the potential for a further complication. While the blade was moved back and forth under a light pressure, the lubricant, mixed with water, could have penetrated into the tip region serving to lower the surface energy at crack initiation. Quite possibly, had the lubricant and water not been used, the $K_{\mathrm{Q}}$ values of group D would then have been higher than those observed.

In this study, no macroplastic deformation was detected. Two sets of typical load-CTOD curves from group $\mathrm{A}$ and group $\mathrm{F}$ are presented in Figure 7 . The same linear features of the $\mathrm{P}-t, \mathrm{CTOD}-t$ and $P-\mathrm{CTOD}$ curves occurred for both groups (and all groups) alike. However, the existence of microplastic deformation was illustrated by the evidence of the dependence of the CTOD on $\rho$ (Fig. 6b). A determination of the plastic-zone size from the measured CTOD value is possible and meaningful if the yield strength of a material is well defined. However, it is difficult to establish at present the process-zone size because the yield strength of columnar S2 ice is not a suitably quantifiable material property. Furthermore, tensile factors in ice may not be preceded by yielding in the classic sense. A related issue is whether a sharp cleavage crack in ice remains automatically sharp or is blunted by certain mechanisms, such as creep or the emission of dislocations from the crack tip. In this study, the cracks in the specimens of groups $\mathrm{E}$ and $\mathrm{F}$ were believed to be the sharp cleavage cracks (while the notch-root radii of the specimens of groups A, B and C, and possibly D, were too large to be considered in this context). The measured CTOD for the specimens of groups E and F seems to indicate the existence of microplastic deformation in the vicinity of the crack tip. This microplastic deformation might involve the emission of dislocations from the crack tip, or movement of the pre-existing dislocations in the area near the crack tip, or other creep mechanisms. More information on this problem is needed before a conclusive remark can be made.

For blunt notches, the maximum tensile stress is located not at the crack tip but at a certain distance ahead of the notch. For this reason, possibly sub-crack nucleation occurs ahead of blunt notches but not ahead of sharp cracks. In a study on the notch effects on tensile behavior of $\mathrm{Ni}_{3} \mathrm{Al}$ alloys, Khadkikar and others (1989) found that instead of initiating from the end of a notch, cracking nucleated at a distance of $250-300 \mu \mathrm{m}$ ahead of the notch root. This finding was explained by a finiteelement analysis of bluntly notched specimens, assuming linear work-hardening material behavior, in which the maximum principal stress was found to be typically at some distance ahead of the notch root (Griffiths and Owen, 1971). While no evidence of sub-crack nucleation was specifically observed in the specimen with blunt notches in this study, the associated higher toughnesses and increased CTOD might have been caused by such events.

\section{CONCLUSIONS}

For metallic materials there is a critical value of the notch-tip radius above which $K_{\mathrm{Q}}$ has a linear dependence on $\rho^{\frac{1}{2}}$ and below which the true plane-strain toughness
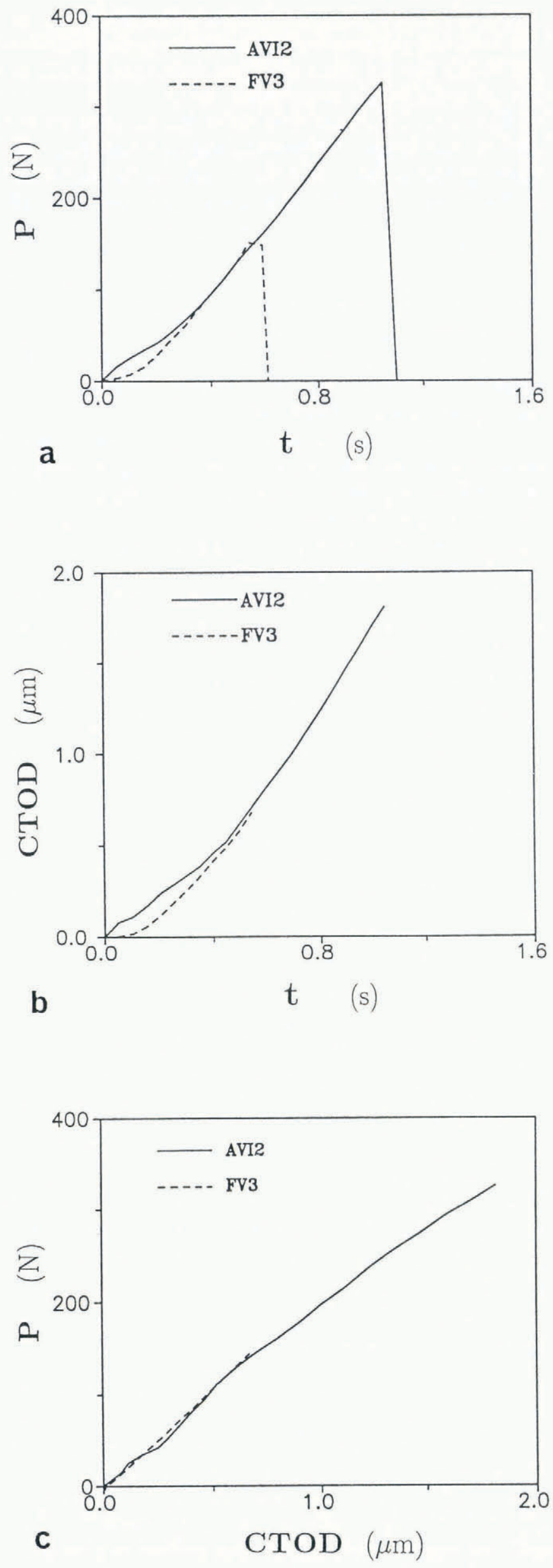

Fig. 7. (a) Load-time curve; (b) CTOD-time curve; (c) Load-CTOD urve for test specimens AV12 and FV3. 
$K_{\text {Ic }}$ is obtained. The $K_{\mathrm{Q}}$ versus $\rho^{\frac{1}{2}}$ plot for S2 ice obtained in this paper revealed a relationship from which it can be argued that there is a necessary minimum notchtip radius that must be attained.

The notch acuity and saw width have a strong influence on the apparent fracture toughness and crack-tip opening displacement of $\mathrm{S} 2$ ice. The mean $K_{\mathrm{Q}}$ values of the specimens with blunt notch tips were as much as $117 \%$ higher than those of the specimens with sharp cracks. The CTOD measured in this study indicates the existence of microplastic deformation in the vicinity of the crack tip at the initiation of unstable fracture.

Crack initiation was observed to initiate, without exception, from the crack tips for specimens with naturally sharp cracks and to initiate offset from the notch tip for some specimens with blunt notches.

The location and notch acuity of the crack tip with respect to the microstructure of the ice in the vicinity of the crack tip significantly influences the apparent fracture toughness; the $K_{\mathrm{Q}}$ value of a specimen with the crack tip ending inside a grain is higher than if the crack tip is located at a grain boundary.

The method of freezing-in a razor blade (group D) creates a sharp crack of known uniform length; especially, it generates a plane-crack front over the whole specimen thickness. There may be experimental set-ups where this feature is especially desirable. For instance, the positioning of the proximity gage for the CTOD measurement requires a precise knowledge of the location of the crack tip prior to testing. It is perhaps no coincidence that the lowest standard deviation for the CTOD measurements (Table 1) was observed for group D.

The methods of forming a blunt notch (groups A, $\mathrm{B}$ and $\mathrm{C}$ ) have little practical meaning for a realistic measurement of the fracture toughness of ice. In fact, Equations (1) and (2) implicitly assume the presence of a sharp crack tip.

The hand-held razor blade and pre-cracking methods are highly repeatable and reliable procedures for forming naturally sharp macrocracks in the fracture-toughness testing of ice. This finding is of crucial importance to the development of a standard method for the fracturetoughness testing of ice.

The very low scatter observed for groups D, E and $\mathrm{F}$ reinforces the conclusion that the particular crackfabrication technique used has been and will continue to be a very important consideration in tests investigating the fracture behavior of ice, be they in the laboratory or in the field.

\section{ACKNOWLEDGEMENTS}

The assistance of L. Briot, C. Ford and J. Johnson in the experimental work is gratefully acknowledged. This study has been supported in part by the U.S. National Science Foundation under grant Nos MSM-86-18798 and MSS-90-07929, in part by the U.S. Army under grant No. DACA89-84-K-0008, and in part by the U.S. Office of Naval Research under grant No. N00014-90-J-1360.

\section{REFERENCES}

ASTM E399-83. 1985. Standard test method for plane- strain fracture toughness of metallic materials. Am. Soc. Test. Mater. Stand. 03.01, 547-582.

Bentley, D. L. J.P. Dempsey, D. S. Sodhi and Y. Wei. 1989. Fracture toughness of columnar freshwater ice from large scale DCB tests. Cold Reg. Sci. Technol., 17(1), 7-20.

Bertolotti, R.L. 1973. Fracture toughness of polycrystalline $\mathrm{Al}_{2} \mathrm{O}_{3}$. J. Am. Ceram. Soc., 56(2), 107.

Cole, D. M. 1990. Reversed direct-stress testing of ice: initial experimental results and analysis. Cold Reg. Sci. Technol., 18(3), 303-321.

Danilenko, V.I. 1985. Determination of crack resistance $\left(K_{\mathrm{Ic}}\right)$ of freshwater ice. Mech. Solids, 20(5), 131-136.

Dempsey, J.P. 1990. Notch sensitivity of ice. In Suprenant, B.A., ed. Serviceability and durability of construction materials. New York, American Society of Civil Engineers, 1124-1133.

Dempsey, J.P. In press. The fracture toughness of ice. In IUTAM/IAHR Symposium on Ice/Structure Interaction, August 14-17, St. John's, Canada. Berlin, etc., Springer Verlag.

Dempsey, J. P., D. Nigam and D. M. Cole. 1988. The flexure and fracture of macrocrystalline S1 type freshwater ice. In Sodhi, D.S., C.H. Luk and N. K. Sinha, eds. OMAE 1988 Houston. Proceedings of the Seventh International Conference on Offshore Mechanics and Arctic Engineering ... presented at ... Houston, Texas, February 7-12, 1988. Vol. IV. Arctic engineering and technology. New York, American Society of Mechanical Engineers, 39-46.

Dempsey, J. P., Y. Wei, S. DeFranco, R. Ruben and R. Frachetti. 1989. Fracture toughness of S2 columnar freshwater ice: crack length and specimen size effects. Part I. In Sinha, N. K., D. S. Sodhi and J.S. Chung, eds. Proceedings of the Eighth International Conference on Offshore Mechanics and Arctic Engineering - 1989 - presented at ... The Hague, The Netherlands, March 19-23, 1989. Vol. IV. Arctic and polar technology. New York, American Society of Mechanical Engineers, 83-89.

Dieter, G. E. 1986. Mechanical metallurgy. Third edition. New York, McGraw-Hill Book Company.

Go, C.-G., S.E. Swartz and K.-K. Hu. 1984. Stress intensity factors for single-edge-notch-beam. J. Eng. Mech., 110, 629-632.

Goodman, D. J. 1977. Creep fracture of ice and surface strain measurements on glaciers and sea ice. (Ph.D. thesis, University of Cambridge.)

Griffiths, J. R. and D. R. J. Owen. 1971. An elastic-plastic stress analysis for a notched bar in plane strain bending. J. Mech. Phys. Solids, 19, 419-431.

Hamza, H. and D.B. Muggeridge. 1979. Plane strain fracture toughness $\left(\mathrm{K}_{\mathrm{Ic}}\right)$ of freshwater ice. In POAC 79. The Fifth International Conference on Port and Ocean Engineering under Arctic Conditions. Proceedings. Vol. 1. Trondheim, University of Trondheim. Norwegian Institute of Technology, 697-707.

Hondoh, T., T. Itoh, S. Amakai, K. Goto and A. Higashi. 1983. Formation and annihilation of stacking faults in pure ice. J. Phys. Chem., 87(21), 4040-4044.

Irwin, G. R. 1964. Structural aspects of brittle fracture. Appl. Mater. Res., 3(2), 65-81. 
Khadkikar, P.S., J.J. Lewandowski and K. Vedula 1989. Notch effects on tensile behavior of $\mathrm{Ni}_{3} \mathrm{Al}$ and $\mathrm{Ni}_{3} \mathrm{Al}+$ B. Metall. Trans., 20A, 1247-1255.

Knott, J.F. 1973. Fundamentals of fracture mechan$i$ cs. London, Butterworths.

Kollé, J. J. 1981. Fracture toughness of ice: crystallographic anisotropy. In POAC 81. The Sixth International Conference on Port and Ocean Engineering under Arctic Conditions, Québec, Canada, July 27-31, 1981. Proceedings. Vol. 1. Québec, Université Laval, 366-374.

Kusumoto, S., N. Kimura, T. Takase and T. Kidera. 1986. Study of fracture toughness of columnar grained ice using large specimens. J. Soc. Mater. Sci., 35(395), 887-891. [In Japanese.]

Liu, H. W. and S. W. Loop. 1972. Fracture toughness of freshwater ice. CRREL Draft Report.

Manoharan, M. and J. J. Lewandowski. 1989. Effect of microstructure and notch root radius on fracture toughness of an aluminium metal matrix composite. Int. J. Fract., 40, R31-R34.

Michel, B. 1978. Ice mechanics. Québec, Les Presses de L'Université Laval.

Michel, B. and R. O. Ramseier. 1971. Classification of river and lake ice. Can. Geotech. J., 8(1), 36-45.

Nixon, W.A. and E.M. Schulson. 1988. The fracture toughness of ice over a range of grain sizes. J. Offshore Mech. Arct. Eng., 110(2), 192-196.
Pabst, R.F. 1974. Determination of $K_{\text {Ic }}$-factors with diamond-saw-cuts in ceramic materials. In Bradt, R. C., D. P. H. Hasselman and F. F. Lange, eds. Fracture mechanics of ceramics. New York and London, Plenum Press, 555-565.

Timco, G. W. and R. M. W. Frederking. 1986. The effects of anisotropy and microcracks on the fracture toughness $K_{\text {Ic }}$ of freshwater ice. In Lunardini, V.J., Y.S. Wang, O. A. Ayorinde and D. V. Sodhi, eds. Proceedings of the Fifth International Offshore Mechanics and Arctic Engineering (OMAE) Symposium presented at ... Tokyo, Japan, April 13-18, 1986. Vol. 4. New York, American Society of Mechanical Engineers, 341-348.

Williams, M. L. 1952. Stress singularities resulting from various boundary conditions in angular corners of plates in extension. J. Appl. Mech., 19, 526-528.

Wilshaw, T.R., C. A. Rau and A.S. Tetelman. 1968. A general model to predict the elastic-plastic stress distribution and fracture strength of notched bars in plane strain bending. Eng. Fract. Mech., 1, 191-211.

Yokobori, T. and S. Konosu. 1977. Effects of ferrite grain size, notch acuity and notch length on brittle fracture stress of notched specimens of low carbon steel. Eng. Fract. Mech., 9(4), 839-847.

The accuracy of the references in the text and in this list is the responsibility of the authors, to whom queries should be addressed.

\section{APPENDIX}

THE S2 ICE-NOTCH ACUITY-TEST DATA

\begin{tabular}{|c|c|c|c|c|c|c|c|}
\hline Type & $h$ & $w$ & $a$ & $P_{f}$ & $\kappa_{\mathrm{Q}}$ & $\kappa$ & CTOD \\
\hline & $\mathrm{mm}$ & $\mathrm{mm}$ & $\mathrm{mm}$ & $\mathrm{N}$ & $\mathrm{kPa} \mathrm{m}^{1 / 2}$ & $\mathrm{kPa} \mathrm{m}^{1 / 2} \mathrm{~s}^{-1}$ & $\mu \mathrm{m}$ \\
\hline AIl & 50 & 101 & 47 & 473 & 208 & 110 & 1.78 \\
\hline 2 & 50 & 101 & 49 & 219 & 102 & 142 & 0.49 \\
\hline 3 & 51 & 102 & 50 & 262 & 125 & 113 & 1.75 \\
\hline AII1 & 48 & 102 & 51 & 539 & 275 & 81 & 2.88 \\
\hline 2 & 52 & 101 & 47 & 314 & 136 & 170 & 1.15 \\
\hline 3 & 48 & 101 & 50 & 543 & 277 & 86 & 2.80 \\
\hline AVl & 43 & 102 & 50 & 307 & 170 & 203 & 1.19 \\
\hline 2 & 43 & 103 & 49 & 445 & 240 & 150 & 1.68 \\
\hline 3 & 45 & 101 & 49 & 246 & 126 & 158 & 0.91 \\
\hline AVI1 & 44 & 101 & 50 & 192 & 104 & 99 & 0.86 \\
\hline 2 & 44 & 101 & 49 & 326 & 174 & 174 & 1.44 \\
\hline 3 & 42 & 102 & 49 & 420 & 231 & 121 & 2.03 \\
\hline BIl & 48 & 102 & 51 & 381 & 194 & 147 & 1.37 \\
\hline 2 & 50 & 101 & 50 & 452 & 218 & 167 & 1.62 \\
\hline 3 & 50 & 100 & 49 & 467 & 225 & 180 & 1.53 \\
\hline BIIl & 52 & 102 & 50 & 492 & 228 & 130 & 1.75 \\
\hline 2 & 51 & 102 & 51 & 563 & 265 & 60 & 1.63 \\
\hline 3 & 49 & 102 & 51 & 319 & 162 & 116 & 1.14 \\
\hline
\end{tabular}


Journal of Glaciology

$\begin{array}{rlllllll}\text { BV1 } & 43 & 102 & 49 & 267 & 143 & 190 & 1.80 \\ 2 & 42 & 102 & 51 & 306 & 179 & 188 & 1.10 \\ 3 & 42 & 102 & 49 & 240 & 134 & 148 & 1.17 \\ \text { BVI1 } & 48 & 101 & 50 & 485 & 243 & 162 & 1.83 \\ 2 & 44 & 101 & 51 & 307 & 176 & 167 & 1.28 \\ 3 & 43 & 102 & 50 & 202 & 112 & 124 & 0.88\end{array}$

\begin{tabular}{rllllrrl}
\hline CI1 & 50 & 99 & 47 & 183 & 85 & 108 & 0.61 \\
2 & 52 & 102 & 49 & 433 & 194 & 129 & 1.53 \\
3 & 53 & 103 & 50 & 206 & 92 & 94 & 0.71 \\
CII1 & 50 & 101 & 50 & 172 & 84 & 114 & 0.56 \\
3 & 45 & 103 & 46 & 185 & 86 & 122 & 0.73 \\
CV1 & 44 & 102 & 53 & 289 & 173 & 115 & 1.22 \\
2 & 43 & 100 & 51 & 189 & 113 & 90 & 0.78 \\
3 & 45 & 101 & 50 & 295 & 162 & 155 & 1.22 \\
CVI1 & 44 & 100 & 47 & 235 & 122 & 128 & 0.99 \\
2 & 44 & 101 & 50 & 343 & 192 & 117 & 1.47 \\
3 & 44 & 102 & 50 & 353 & 193 & 128 & 1.22 \\
\hline
\end{tabular}

\begin{tabular}{rllllrrl}
\hline DI2 & 56 & 101 & 49 & 191 & 80 & 89 & 0.72 \\
3 & 53 & 103 & 52 & 244 & 116 & 116 & 0.89 \\
DII1 & 46 & 102 & 49 & 197 & 98 & 123 & 0.68 \\
2 & 47 & 101 & 47 & 184 & 88 & 110 & 0.60 \\
3 & 48 & 101 & 50 & 184 & 91 & 114 & 0.58 \\
DV1 & 45 & 102 & 53 & 149 & 86 & 143 & 0.57 \\
2 & 45 & 102 & 50 & 172 & 91 & 139 & 0.60 \\
3 & 52 & 100 & 50 & 136 & 66 & 109 & 0.57 \\
DVI1 & 43 & 101 & 48 & 181 & 96 & 137 & 0.59 \\
2 & 43 & 99 & 47 & 185 & 100 & 153 & 0.69 \\
3 & 42 & 102 & 48 & 153 & 83 & 146 & 0.38 \\
\hline
\end{tabular}

\begin{tabular}{rllllrll}
\hline EI1 & 49 & 101 & 50 & 189 & 95 & 136 & 0.74 \\
2 & 53 & 101 & 48 & 251 & 108 & 120 & 0.68 \\
3 & 50 & 102 & 51 & 201 & 101 & 151 & 0.74 \\
EII1 & 48 & 101 & 48 & 184 & 87 & 124 & 0.50 \\
2 & 49 & 101 & 51 & 213 & 109 & 136 & 0.76 \\
3 & 47 & 102 & 52 & 161 & 87 & 108 & 0.58 \\
EV1 & 46 & 101 & 51 & 187 & 103 & 103 & 1.47 \\
2 & 44 & 102 & 52 & 157 & 92 & 153 & 0.68 \\
3 & 45 & 103 & 49 & 170 & 87 & 124 & 0.48 \\
EVI1 & 42 & 103 & 58 & 129 & 90 & 120 & 0.57 \\
2 & 43 & 103 & 50 & 180 & 98 & 151 & 0.72 \\
3 & 47 & 100 & 49 & 208 & 107 & 142 & 0.72 \\
& & & & & & & \\
\hline & & & & & & & \\
FI1 & 53 & 102 & 49 & 227 & 101 & 126 & 0.63 \\
2 & 53 & 102 & 51 & 240 & 112 & 140 & 0.63 \\
3 & 52 & 101 & 50 & 218 & 101 & 118 & 0.63 \\
FII1 & 45 & 101 & 49 & 197 & 103 & 171 & 1.26 \\
2 & 47 & 102 & 53 & 158 & 88 & 110 & 0.73 \\
3 & 49 & 101 & 50 & 166 & 83 & 119 & 0.83 \\
FV1 & 44 & 102 & 49 & 197 & 104 & 173 & 0.63 \\
2 & 43 & 102 & 50 & 180 & 102 & 145 & 0.59 \\
3 & 43 & 102 & 50 & 181 & 101 & 144 & 0.68 \\
FVI1 & 44 & 102 & 50 & 163 & 89 & 148 & 0.49 \\
2 & 45 & 100 & 49 & 191 & 102 & 128 & 0.78 \\
3 & 43 & 102 & 48 & 169 & 90 & 128 & 0.50 \\
& & & & & & & \\
& & & & & & &
\end{tabular}

MS received 20 March 1990 and in revised form 22 February 1991 